\title{
Industrial Bearing Fault Detection Using Time-Frequency Analysis
}

\author{
Yasmina Bella \\ Electrical Engineering Department \\ Ferhat Abbes Setif 1 University \\ Setif, Algeria \\ b_yasmina2014@univ-setif.dz
}

\author{
Abdelhak Oulmane \\ Department of Mechanical Engineering \\ Polytechnic School of Montreal \\ Montreal, Canada \\ abdelhak.oulmane@polymtl.ca
}

\author{
Mohammed Mostefai \\ Electrical Engineering Department \\ Ferhat Abbes Setif 1 University \\ Setif, Algeria \\ mostefai@,univ-setif.dz
}

\begin{abstract}
Time-frequency fault detection techniques were applied in this study, for monitoring real life industrial bearing. For this aim, an experimental test bench was developed to emulate the bearing rotating motion and to measure the induced vibration signals. Dedicated software was used to analyze the acquired measurements in the time-frequency domain using several distributions with varying resolution. Results showed that each fault type exhibits a specific behavior in the time-frequency domain, which is exploited in the localization of the faulty component.
\end{abstract}

Keywords-time-frequency domain; industrial bearing; nondestructive test; vibration analysis

\section{INTRODUCTION}

Enhancement of the production system dependability is a major issue faced by competitive industrial companies. In this context, the predictive maintenance can play a fundamental role in improving the production system reliability and economic efficiency. In fact, the predictive maintenance is a corrective action applied on the equipment, systems or installations based on the previous knowledge of the operation conditions or performances. Hence, using fault monitoring algorithms can provide real time information about the system health and allows a reliable maintenance decision-making tool [1]. In rotating machinery, the fault monitoring of the rolling element bearings (REBs) is of great practical interest. Actually, bearing damage causes $40 \%$ of the total amount of failures in an induction motor [2]. A comprehensive review of the recent advances of REBs monitoring techniques can be found in [3]. Current signature analysis method for the diagnosis of bearing faults forms an area of increasing scientific interest. The main idea beyond this technique is detecting faults based on the change of the stator current spectrum of the induction motor. This change causes a variation of the load and irregularities in the magnetic field. The latter affects the mutual and selfinductance and leads to side bands across the line frequency.

Despite the advantages of the current signature method, mechanical vibration signal analysis remains more immediate, simple and rich source of information for understanding the defected bearings (DBs) behavior [4]. Vibration signals acquired from bearings can be either stationary or nonstationary. The stationary signals are characterized by time- invariant statistical properties (moments, densities etc.), however, the statistical properties of a non-stationary signal variy over time $[5,6]$. In fact, bearing vibration signals are almost always non-stationary since they are inherently dynamic (e.g. speed and load condition change over time) [7]. Joint time-frequency analysis is an effective approach for addressing this issue, using signals which are presented in a timefrequency amplitude/energy density 3D space. Hence, both the constituent frequency components and their time variation properties can be detected [8-10]. Several time-frequency analysis methods are developed, e.g. short time Fourier transform [11], wavelet transform [12, 13], bilinear/quadratic time-frequency distributions including Cohen and affine classes distributions based on Wigner-Ville distribution [14-16]. In the same context, adaptive optimal kernel methods allow adaptive kernel modification and make the time-frequency distribution suitable for signal structures identification [17]. To suppress the cross-terms and improve time-frequency resolution, the reassignment method has been proposed in [18]. In order to deal with the non-linearity and non-Gaussianity of signals, time-varying higher order spectrum methods such as Wigner higher order spectrum were developed [19]. It is worth mentioning that most of the above mentioned time-frequency analysis methods have been applied to machinery fault diagnosis [20, 21]. In this paper, time-frequency vibration analysis method is used for fault detection of real world industrial bearings motivated by the promising results in induction motor condition monitoring field [22, 23]. For this aim, a bearing experimental test bench has been developed and the acquired vibration signals were examined using T-F ANALYSIS toolbox. The used approach consists of comparing several time-frequency bearing performances under different operation conditions.

\section{NON-DESTRUCTIVE BEARING TESTING BASED ON TIME- FREQUENCY ANALYSIS}

Vibration analysis is one of the most usual non-destructive methods utilized to evaluate the bearing conditions in an operating machine. Different bearing faults induce different patterns in the time-frequency plane. In this section we give the frequency values associated to each type of bearing element defect (cage, ball, inner and outer raceways). Thereafter, in order to overcome the drawbacks of the traditional spectral 
analysis techniques, quadratic time-frequency distributions approaches are introduced. These techniques allow easier and more precise discrimination between defect and normal bearing. This section represents the theoretical background of the experimental study.

\section{A. Bearings Fault Frequencies}

The rolling surface damage is caused by fatigue because of the presence of high forces at the contact points. More specifically, vibrations are produced by the impacts that occur when the surface of one component strikes another surface. Industrial bearings exhibit special behavior in the frequency domain. In fact, as the inner or outer rings rotate, the balls moving over the running surface excite the bearing structure and cause vibrations. When the outer or the inner raceway, the cage or the balls are defected, the amplitude of the vibrations is amplified. By examining the frequency spectrum of a bearing vibrational signal, specific frequencies are amplified when a fault occurs. The bearing fault frequencies can be calculated using the formulas given in [19] as follows (see Figure 1):

$$
\begin{aligned}
& \mathrm{f}_{\mathrm{CF}}=1 / 2 \mathrm{f}_{\mathrm{R}}\left(1-\frac{\mathrm{D}_{\mathrm{B}} \cos (\theta)}{\mathrm{D}_{\mathrm{P}}}\right) \\
& \mathrm{f}_{\mathrm{BF}}=\mathrm{D}_{\mathrm{P}} / 2 \mathrm{D}_{\mathrm{B}} \cdot \mathrm{f}_{\mathrm{r}}\left(1-\frac{\mathrm{D}_{\mathrm{B}}^{2} \cos ^{2}(\theta)}{\mathrm{D}_{\mathrm{P}}^{2}}\right) \\
& \mathrm{f}_{\mathrm{ORF}}=\mathrm{N}_{\mathrm{B}} / 2 \cdot \mathrm{f}_{\mathrm{r}}\left(1+\frac{\mathrm{D}_{\mathrm{B}} \cos (\theta)}{D_{\mathrm{P}}}\right) \\
& \mathrm{f}_{\mathrm{IRF}}=\mathrm{N}_{\mathrm{B}} / 2 \cdot \mathrm{f}_{\mathrm{r}}\left(1-\frac{\mathrm{D}_{\mathrm{B}} \cos (\theta)}{D_{\mathrm{P}}}\right)
\end{aligned}
$$

where: $f_{C F}$ is the cage fault frequency, $f_{B F}$ the ball fault frequency, $\mathrm{f}_{\mathrm{ORF}}$ the outer raceway fault frequency and $\mathrm{f}_{\mathrm{IRF}}$ the inner raceway fault frequency.
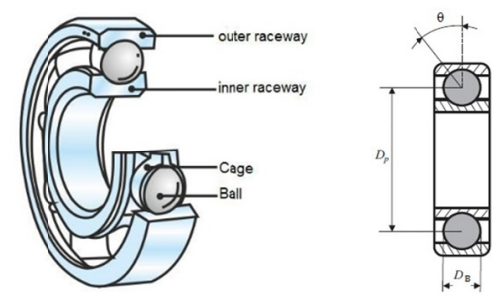

Fig. 1. Representation of ball bearing characteristics.

However, because of the bearing components sliding motion, the characteristic frequencies may be slightly different from their calculated values (1\%-2\%). Hence, fault isolation can be performed by comparing the measured characteristic frequency with the theoretical ones. The bearing deterioration not only increases the amplitude of the vibration frequencies but also generates harmonics associated to these frequencies caused by the amplitude modulation. The deterioration phenomenon can be recognized by an amplitude modulation equal to the shaft rotation frequency $f_{0}$ around the bearing defects frequencies [24].

\section{B. Vibration Analysis Tools}

A straightforward way to obtain the frequency spectrum of a time-varying signal $\mathrm{x}(\mathrm{t})$ is to localize the signal by modulating it with a window function $h$ [25], before performing the short-time Fourier transform (STFT) to obtain the frequency content of the signal in the region of the window as follows:

$$
F_{x}(t, f)=\int_{-\infty}^{+\infty} x(u) h^{*}(u-t) e^{-2 i \pi f u} d u
$$

where $*$ denotes the complex conjugate [3]. For the spectral representation around $t$, we simply move by translation window $\mathrm{h}$ and we perform a Fourier transformation on the windowed signal as well. However, the spectrogram of the signal $x(t)$ can be estimated by computing the squared magnitude of the STFT, as follows:

$$
S_{x}(t, f)=\left|F_{x}(t, f)\right|^{2}
$$

On the other hand, time-frequency analysis includes the techniques that study a signal in both time and frequency domains simultaneously, using various time-frequency representations. For instance, the class of quadratic timefrequency distributions is considered the most appropriate method for the analysis and processing of non-stationary signals in many practical applications:

$$
\begin{gathered}
P_{z}(t, f)=\int_{-\infty}^{+\infty} \int_{-\infty}^{+\infty} K(u, v, t, f) z(u) z^{*}(v) d u d v \\
=\int_{-\infty}^{+\infty} \int_{-\infty}^{+\infty} K^{\wedge}(u, v, t, f) Z(u) Z^{*}(v) d u d v
\end{gathered}
$$

where $\mathrm{z}(\mathrm{u}), \mathrm{Z}(\mathrm{f})$ are the studied signal and $\mathrm{K}(\mathrm{u}, \mathrm{v}, \mathrm{t}, \mathrm{f})$, $\mathrm{K}^{\wedge}(\mathrm{u}, \mathrm{v}, \mathrm{t}, \mathrm{f})$ are the transition kernels. A special class of timefrequency transformation is the Cohen class given by:

$\int_{-\infty}^{+\infty} \int_{-\infty}^{+\infty} \int_{-\infty}^{+\infty} \mathrm{e}^{2 i \pi \xi(s-\tau)} \mathrm{f}(\xi, \tau) \mathrm{z}\left(\mathrm{s}+\frac{\tau}{2}\right) \mathrm{z}^{*}\left(\mathrm{~s}-\frac{\tau}{2}\right) \mathrm{e}^{-2 i \pi f \tau} \mathrm{d} \xi \mathrm{dfd} \tau$

where $f(\xi, \tau)$ is the observation window verifying $\mathrm{f}(\xi, \tau)=\mathrm{f}(-\xi,-\tau)$. If the function $\mathrm{f}(\xi, \tau)$ is independent of $\xi$ and $\tau$ (for example $\mathrm{f}(\xi, \tau)=1$ ), we get the Wigner-Ville distribution given by (6):

$$
\begin{gathered}
\mathrm{W}_{\mathrm{z}}(\mathrm{t}, \mathrm{f})=\int_{-\infty}^{+\infty} \mathrm{z}\left(\mathrm{t}+\frac{\mathrm{u}}{2}\right) \mathrm{z}^{*}\left(\mathrm{t}-\frac{\mathrm{u}}{2}\right) \mathrm{e}^{-2 \mathrm{i} \pi \mathrm{fu}} \mathrm{du} \\
=\int_{-\infty}^{+\infty} \mathrm{Z}\left(\mathrm{f}+\frac{\mathrm{v}}{2}\right) \mathrm{Z}^{*}\left(\mathrm{f}-\frac{\mathrm{v}}{2}\right) \mathrm{e}^{-2 i \pi f \mathrm{u}} \mathrm{d} v
\end{gathered}
$$

To reduce the oscillatory inferences of the Wigner-Ville distribution, we apply a separated smoothing in time and frequency using the following time-frequency window: $\varphi(t, f)=g(t) H(f)$. This distribution, known by the smoothed Wigner-Ville distribution, is given by (7):

$$
\int_{-\infty}^{+\infty} \int_{-\infty}^{+\infty} \varphi\left(\mathrm{t}_{\mathrm{o}}, \mathrm{f}_{\mathrm{o}}\right) \mathrm{W}_{\mathrm{z}}\left(\mathrm{t}-\mathrm{t}_{\mathrm{o}}, \mathrm{f}-\mathrm{f}_{\mathrm{o}}\right) \mathrm{dt}_{\mathrm{o}} \mathrm{df}_{\mathrm{o}}
$$

$\mathrm{g}$ and $\mathrm{h}$ are even and real windows with $\mathrm{h}(0)=\mathrm{g}(0)=1$.

Another distribution that allows the minimization of the oscillatory interference effect is the Choi-Williams distribution. For this distribution, the function $\mathrm{f}$ has the following form:

$$
\mathrm{f}(\xi, \tau)=\mathrm{e}^{\frac{-(\pi \xi \tau / \sigma)^{2}}{2}}
$$

Hence, the Choi-Williams distribution is given by the following: 


$$
\mathrm{P}(\mathrm{t}, \mathrm{f})=\sqrt{\frac{2}{\pi}} \int_{-\infty}^{+\infty} \int_{-\infty}^{+\infty} \frac{\sigma}{|\tau|} \mathrm{e}^{-2 \sigma^{2}(\mathrm{~s}-\mathrm{t})^{2} / \tau^{2}} \mathrm{z}\left(\mathrm{s}+\frac{\tau}{2}\right) \mathrm{z}^{*}\left(\mathrm{~s}-\frac{\tau}{2}\right) \mathrm{e}^{-2 i \pi f \tau} \mathrm{dsd} \tau
$$

Actually, if we choose the kernel function as:

$$
f(\psi, \tau)=\frac{\sin 2 \pi a \tau \psi}{2 \pi a \tau \psi}
$$

where a is a constant. This distribution is called Born-Jordan distribution and has the following form:

$$
P(t, f)=\int_{-\infty}^{+\infty}\left[\frac{1}{2 a|\tau|} \int_{t-a \tau}^{t+a \tau} z\left(s+\frac{\tau}{2}\right) z^{*}\left(s+\frac{\tau}{2}\right) d s\right] e^{-2 i \pi f \tau}
$$

We emphasize that each time-frequency distribution gives a different resolution quality which allows accurate analysis of the signal under study as illustrated below.

\section{EXPERIMENTAL STUDY STEPS}

A general description of the bearing structure is given and then the theoretical fault frequencies are calculated using the equations of the previous section. In order to take advantage of the developed theory, we launched several experiments in a dedicated experimental test bench. Finally, for making decisions about the faulty state, we evaluated the acquired vibration measurements using T-F ANALYSIS toolbox which offers a wide range of methods in time, frequency and timefrequency analysis. The advantages of signal analysis in the time-frequency domain are:

- It provides a representation of the signal in three dimensions (amplitude-time-frequency)

- It detects and follows the development of defects that generate a low vibration power.

- It supervises machines in which the normal operating process produces high amplitude of periodic shocks.

T-F ANALYSIS toolbox, also offers more applications in automatic classification of rotating machinery, image processing through usage of Fourier descriptors and neural networks.

\section{A. Bearing Description and Theorical Fault Frequencies Computation}

We used the Pratt \& Whitney PW100\#5 bearing, this bearing is a single row ball model with radial contact (Figure 2). The technical specifications of bearing that we need to calculate the theoretical fault frequencies are taken from the data sheet provided by the constructor (Table I).

TABLE I. BEARING TECHNICAL SPECIFICATIONS

\begin{tabular}{|c|c|}
\hline P \& W Bearing ID & PW100\#5BRG roller bearing \\
\hline Inner diameter & 2.8347 " $2.8350 "$ \\
\hline Outer diameter & $3.9292{ }^{\prime} 3.9272$ " \\
\hline Pitch diameter & $3.04165 "$ \\
\hline Width & $0.6255^{\prime \prime} 0.630 "$ \\
\hline Contact Angle & $0^{\circ}$ \\
\hline Operating speed 1 & $1000 \mathrm{rpm}$ \\
\hline Operating speed 2 & $2000 \mathrm{rpm}$ \\
\hline
\end{tabular}

PW100\#5 bearing is used for the shaft of the gearbox. This bearing was collected from Bombardier Company and has been identified as one of the most problematic components.
Furthermore, the frequencies associated with the different bearing defects are calculated using (1a)-(1d) and are summarized in Table II where $f_{r}$ is the bearing rotating frequency.

TABLE II. BEARING THEORETICAL FAULT FREQUENCIES

\begin{tabular}{|c|c|c|c|c|}
\hline $\mathbf{f}_{\mathbf{r}}$ & $\mathbf{f}_{\mathbf{C F}}$ & $\mathbf{f}_{\text {ORF }}$ & $\mathbf{f}_{\text {IRF }}$ & $\mathbf{f}_{\text {BF }}$ \\
\hline $16.66 \mathrm{~Hz}$ & $7.64 \mathrm{~Hz}$ & $108.32 \mathrm{~Hz}$ & $91.71 \mathrm{~Hz}$ & $99.54 \mathrm{~Hz}$ \\
\hline $33.33 \mathrm{~Hz}$ & $15.28 \mathrm{~Hz}$ & $216.64 \mathrm{~Hz}$ & $183.42 \mathrm{~Hz}$ & $199.08 \mathrm{~Hz}$ \\
\hline
\end{tabular}

\section{B. Experimental Tests and Measurement Acquisition}

Several tests on the bearing were carried out in the Mechanics Department Laboratory at the Ecole Polytechnique de Montreal. The test bench was designed at the laboratory of the applied mechanics section. The latter consists of the following elements: A rotor system consisting of a shaft supported at its ends by an assembly of two SKF bearings that is connected to a gearbox via a transmission belt system. The entire system is driven by a $2 \mathrm{HP}$ electric motor rated at $3600 \mathrm{rpm}$ and supported by a set of two $67 \mathrm{lb} / \mathrm{ft} \mathrm{H}$-weighted beams each. The test bench is $1750 \mathrm{~mm}$ long and $210 \mathrm{~mm}$ wide (Table III). The test bench is designed to test typical defects in rotating machinery such as damaged bearings, mass imbalance and gears. All bearings are mounted on a clamping sleeve and can be easily disassembled. We have designed an internal and external clamping sleeve assembly to fit all Pratt \& Whitney bearing sizes.

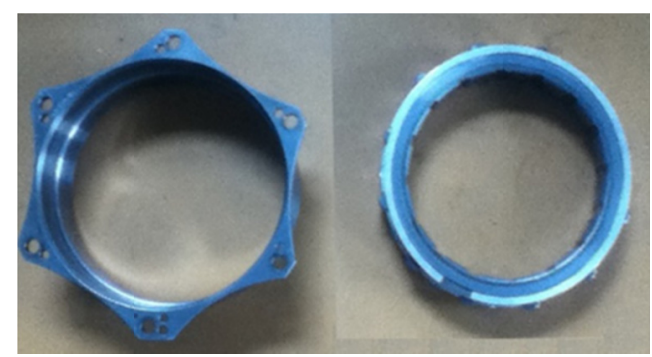

Fig. 2. Pratt \& Whitney bearing considered for test.

TABLE III. TEST BENCH TECHNICAL SPECIFICATIONS

\begin{tabular}{|c|c|c|}
\hline Components & Specifications & Manufacturers \\
\hline Base & $2 \mathrm{H}-$ Beams W8x8 67lb/ft & Prometo \\
\hline Motor & $2 \mathrm{Hp}, 3600 \mathrm{rpm}, 575 \mathrm{Volts}$ & Toshiba \\
\hline Couplings & $7 / 8$ inch-linch & Rex Omega \\
\hline Bearing House & SNL 510 $-\mathrm{H} 310-1210 \mathrm{EKTN} 9$ & SKF Canada \\
\hline
\end{tabular}

Three accelerometers were used, A1, A2 and A3 (Figure 3) which were connected to a computer for data acquisition. The accelerometer A3 was positioned horizontally over the bearing for monitoring the bearing faults, A2 was positioned vertically on the side of the bearing for monitoring the shaft faults and A1 was positioned horizontally on the spindle for monitoring the motor and thus test equipment condition. We emphasize that only the data from A1 were analyzed, as we are conducting bearing fault diagnosis. The rest of sensors' information were used for equipment monitoring. The test bench can be disassembled in order to remove the shaft along with the old bearing (Figure 4, left). Then, as illustrated in the lower right 
Figure 4 , the new bearing is expanded by heating to $110^{\circ} \mathrm{C}$ in order to insure successful insertion into the shaft. Thereafter, the stretch bench is reassembled and carefully calibrated. The tests were carried out at two different rotational speeds (Sp1, Sp2) of $1000 \mathrm{rpm}$ and 2000rpm respectively (Table IV). The speed range was decided after the fact that the peak factor of the fault frequency reacts well over the range of rotation from 500rpm to 2200rpm [26]. At low and high-speed range, the signal is less marked, less amplified by the defect, i.e. for highspeed, the amplitude generated by the fault is not clearly distinguishable from the background noise and for low-speed no acceleration is generated. For high rotational speeds, due to excessive noise, there is an imminent risk of damaging the test bench.

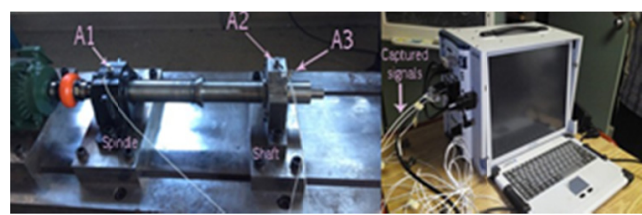

Fig. 3. Experimental test bench.

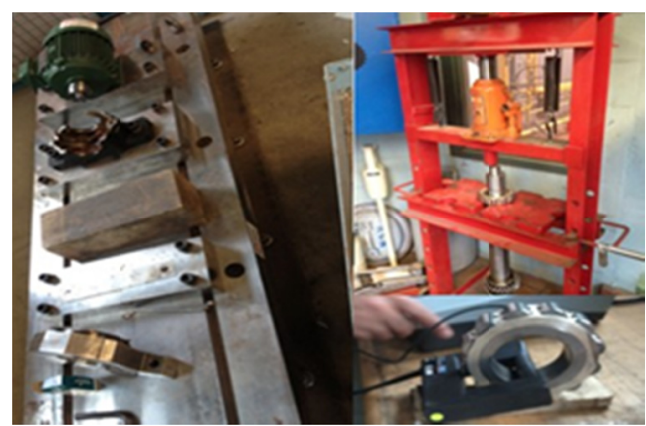

Fig. 4.

Assembling and disassembling of the bearings from the bench.

TABLE IV. TEST SPEEDS

\begin{tabular}{|c|c|c|}
\hline & Rotating speed (rpm) & Rotating speed (Hz) \\
\hline Sp1 & 1000 & 16.66 \\
\hline Sp2 & 2000 & 33.33 \\
\hline
\end{tabular}

Experimental results are presented in a chronological order without taking into consideration the times of acceleration and deceleration i.e. we only deal with the following time intervals: $\mathrm{t} 1 \mathrm{a}-\mathrm{t} 1 \mathrm{~b}$ and $\mathrm{t} 2 \mathrm{a}-\mathrm{t} 2 \mathrm{~b}$ (Figure 5). The acceleration measurements are acquired using NI PMA61115 Portable Monitor and then processed using TF-ANALYSIS software.

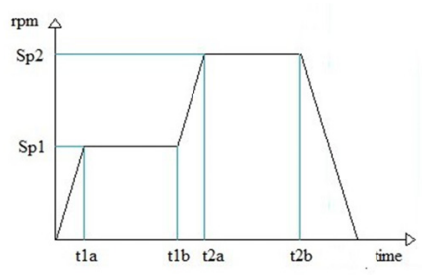

Fig. 5. Speed diagram for PW100\#5

For fault diagnosis purposes, only three parameters were considered: sampling frequency, time window length and frequency window length. It was essential to find a trade-off between time and frequency resolution because if the precision is obtained in the time domain then it is lost in the frequency domain and vice versa. Hence, in order to obtain the best possible resolution for a particular case a manual trial method was applied under the condition that both time and frequency window lengths need to satisfy the equation $2 n-1$, where $n$ is a positive integer [3].

\section{Discussion and Validation of Results}

For different rotational speed values, the graphs of different distributions obtained by the time-frequency method are analyzed. By adjusting the software parameters for different distributions of Choi-Williams and Born-Jordan one seeks a better resolution of the signal.

\section{1) Measurement Results for Time-Period t1a-t1b (Sp1)}

From Figures 6 and 7, the distribution of Choi-Williams presents a better resolution compared to the Born-Jordan distribution. The signal modulation indicates the presence of non-stationary signal. The latter confirms the presence of defects in bearing. The signal spectrum graph (Figure 8) shows a frequency peak, which corresponds to the value of $91 \mathrm{~Hz}$. From the spectrum graph, we notice that the peak frequency is almost equal to the inner raceway calculated fault frequency $f_{\text {IRF }}$ value, which has a value of $91.71 \mathrm{~Hz}$ (Table II).

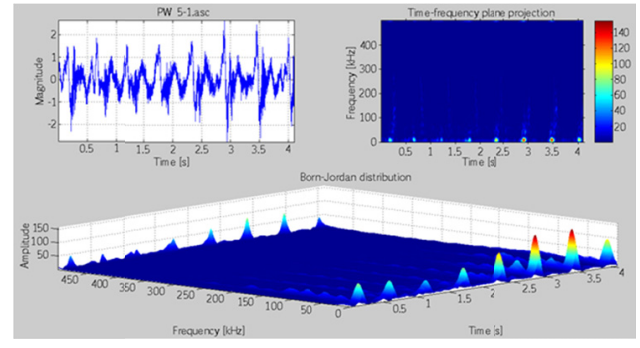

Fig. 6. Born-Jordan distribution for speed of 1000rpm.

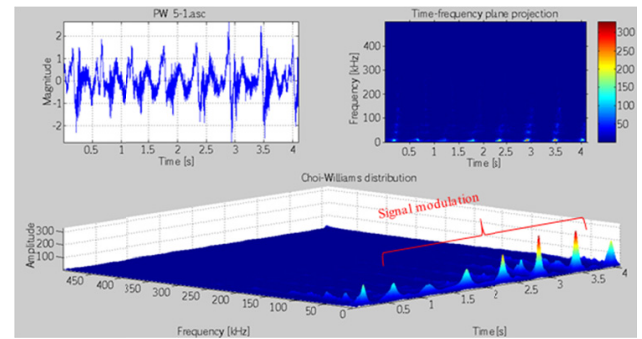

Fig. 7. Choi-Williams distribution for speed of 1000rpm.

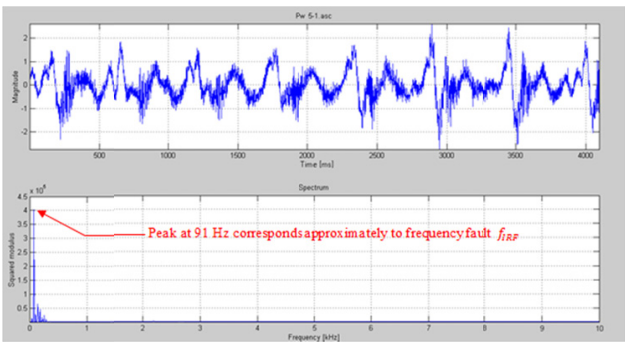

Fig. 8. Spectrum frequency analysis for speed of 1000rpm. 
2) Measurement results for Time-Period $t 2 a-t 2 b(S p 2)$

For this time-period, the rotation speed is doubled to the value of 2000rpm (Sp2). According to the Born-Jordan and Choi-Williams distribution graphs (Figures 9 and 10), we note that the modulation number has almost doubled. These modulations are present at low frequency, which confirms the presence of defects. As in Sp1, the peak frequency of $183 \mathrm{~Hz}$ from the spectrum (Figure 11) corresponds approximately to the fault frequency $\mathrm{f}_{\mathrm{IRF}}$ (Table II), which equals to $183.42 \mathrm{~Hz}$. We noticed that for different rotating speeds, the timefrequency transformations indicate the apparition of $f_{I R F}$ frequency fault. To validate the obtained results we calculate the percentage of relative error between the theoretical value and the experimental value of fault frequency $\left(\% \Delta \mathrm{f}_{\mathrm{IRF}}\right)$ which is calculated by (12):

$$
\% \Delta \mathrm{f}_{\text {IRF }}=\frac{\left|\left(\mathrm{f}_{\text {IRF }}\right)_{\text {experimental }}-\left(\mathrm{f}_{\text {IRF }}\right)_{\text {theorical }}\right|}{\left(\mathrm{f}_{\text {IRF }}\right)_{\text {theorotical }}} \times 100
$$

The experimental fault frequency $\mathrm{f}_{\mathrm{IRF} \text { experimental }}$ for rotating speeds of $1000 \mathrm{rpm}$ and $2000 \mathrm{rpm}$ is $0.77 \%$ and $0.23 \%$ less than the theoretically fault frequency respectively (Table V).

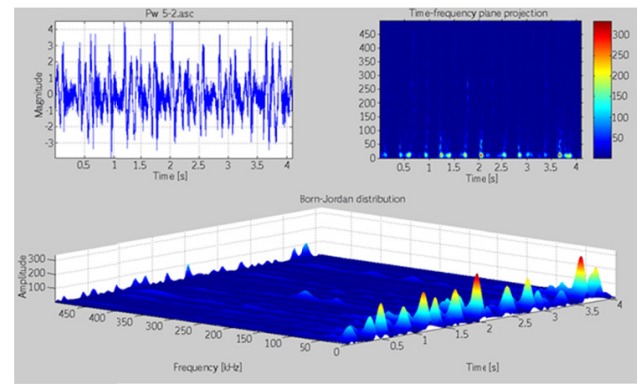

Fig. 9. Born-Jordan distribution for speed of 2000rpm.

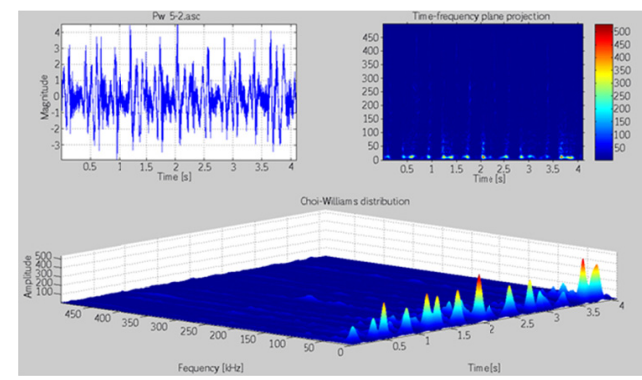

Fig. 10. Choi-Williams distribution for speed of 2000rpm.

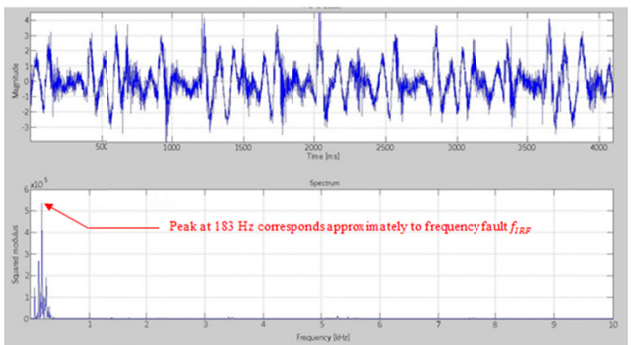

Fig. 11. Spectrum frequency analysis for speed of 2000rpm.

The validity of the measurements is demonstrated by the small difference between the theoretical and measured fault frequencies, which is less than $1 \%\left(\% \Delta \mathrm{f}_{\mathrm{IRF}}<1 \%\right)$.

TABLE V. SUMMARY TABLE FOR THE MEASUREMENT ERROR.

\begin{tabular}{|c|c|c|c|}
\hline $\begin{array}{c}\text { Rotating speed } \\
\mathbf{f r}\end{array}$ & $\begin{array}{c}\text { Theoretical } \\
\mathbf{f}_{\text {IRF }}\end{array}$ & $\begin{array}{c}\text { Experimental } \\
\mathbf{f}_{\text {IRF }}\end{array}$ & $\begin{array}{c}\text { Relative error } \\
\mathbf{\%} \mathbf{\Delta} \mathbf{f}_{\text {IRF }}\end{array}$ \\
\hline $1000 \mathrm{rpm}$ & $91.71 \mathrm{~Hz}$ & $91 \mathrm{~Hz}$ & $0.77 \%$ \\
\hline $2000 \mathrm{rpm}$ & $183.42 \mathrm{~Hz}$ & $183 \mathrm{~Hz}$ & $0.23 \%$ \\
\hline
\end{tabular}

\section{CONCLUSION}

In this paper, a time-frequency domain fault detection and isolation method was applied for industrial bearing. The obtained results are valid in relation to the theoretically calculated results. The difference of the experimentally obtained results and the theoretical ones is less than $1 \%$. This shows the effectiveness of the used technique in extracting important information about the bearing health from the vibration measurements. Further directions of this work will include the study of fault severity and real time bearing monitoring which provides important information for a wide spectrum of critical applications such as aeronautic and transportation. In fact, real time detection facilitates making decisions (system stop, curative maintenance, predictive maintenance, and control law reconfiguration) in order to avoid human and material disasters.

\section{REFERENCES}

[1] E. L. Bonaldi, G. Lambert-Torresm, J. G. B. da Silva, L. E. de Lacerda de Oliveira, L. E. B. da Silva, "Predictive maintenance by electrical signature analysis to induction motors", available at: http://dx.doi.org/10.5772/48045, INTECH Open Access Publisher, 2012

[2] S. Patidar, P. Kumar Soni, "An overview on vibration analysis techniques for the diagnosis of rolling element bearing faults", International Journal of Engineering Trends and Technology, Vol. 4, No. 5, pp. 1803-1809, 2013

[3] S. Nandi, H. A. Toliyat, X. Li, "Condition monitoring and fault diagnosis of electrical motors-a review", IEEE Transactions on Energy Conversion, Vol. 20, No. 4, pp. 719-729, 2005

[4] S. Choi, B. Akin, M. M. Rahimian, H. A. Toliyat, "Implementation of a fault-diagnosis algorithm for induction machines based on advanced digital-signal-processing techniques", IEEE Transactions on Industrial Electronics, Vol. 58, No. 3, pp. 937-948, 2011

[5] F. E. H. Montero, O. C. Medina, "The application of bispectrum on diagnosis of rolling element bearings: A theoretical approach", Mechanical Systems and Signal Processing, Vol. 22, No. 3, pp. 588-596, 2008

[6] S. Guoji, S. McLaughlin, X. Yongcheng, P. White, "Theoretical and experimental analysis of bispectrum of vibration signals for fault diagnosis of gears", Mechanical Systems and Signal Processing, Vol. 43, No. 1, pp. 76-89, 2014

[7] C. Li, V. Sanchez, G. Zurita, M. C. Lozada, D. Cabrera, "Rolling element bearing defect detection using the generalized synchrosqueezing transform guided by time-frequency ridge enhancement", ISA Transactions, Vol. 60, pp. 274-184, 2015

[8] L. Cohen, Time-Frequency Analysis, Prentice Hall, 1995

[9] S. Qian, D. Chen, Joint Time-Frequency Analysis, Prentice Hall, 1996

[10] P. Flandrin, Time-Frequency/Time-Scale Analysis, Academic press, 1998

[11] A. Prudhom, J. Antonino-Daviu, H. Razik, V. Climente-Alarcon, "Timefrequency vibration analysis for the detection of motor damages caused by bearing currents", Mechanical Systems and Signal Processing, Vol. 84, No. A, pp. 747-762, 2015 
[12] J. Chen, J. Pan, Z. Li, Y. Zi, X. Chen, "Generator bearing fault diagnosis for wind turbine via empirical wavelet transform using measured vibration signals", Renewable Energy, Vol. 89, pp. 80-92, 2016

[13] N. Hess-Nielsen, M. V. Wickerhauser, "Wavelets and time-frequency analysis", Proceedings of the IEEE, Vol. 84, No. 4, pp.523-540, 1996

[14] L. Cohen, "Time-frequency distributions-a review", Proceedings of the IEEE, Vol. 77, No. 7, pp. 941-981, 1989

[15] O. Rioul, P. Flandrin, "Time-scale energy distributions: A general class extending wavelet transforms", IEEE Transactions on Signal Processing, Vol. 40, No. 7, pp. 1746-1757, 1992

[16] P. Flandrin, P. Goncalves, "Geometry of affine time-frequency distributions", Applied and Computational Harmonic Analysis, Vol. 3, No. 1, pp. 10-39, 1996

[17] A. Bermanis, G. Wolf, A. Averbuch, "Diffusion-based kernel methods on euclidean metric measure spaces", Applied and Computational Harmonic Analysis, Vol. 41, No. 1, pp. 190-213, 2016

[18] L. Gelman, I. Petrunin, J. Komoda, "The new chirp-wigner higher order spectra for tran- sient signals with any known nonlinear frequency variation", Mechanical Systems and Signal Processing, Vol. 24, No. 2, pp. 567-571, 2010

[19] L. Saidi, F. Fnaiech, H. Henao, G. A. Capolino, G. Cirrincione, "Diagnosis of broken-bars fault in induction machines using higher order spectral analysis", ISA Transactions, Vol. 52, No. 1, pp. 140-148, 2013

[20] Z. Feng, M. Liang, F. Chu, "Recent advances in time-frequency analysis methods for machinery fault diagnosis: a review with application examples", Mechanical Systems and Signal Processing, Vol. 38, No. 1, pp. 165-205, 2013

[21] A. Rai, S. H. Upadhyay, "A review on signal processing techniques utilized in the fault diagnosis of rolling element bearings", Tribology International, Vol. 96, pp. 289-306, 2016

[22] C. Yang, T. J. Kang, D. Hyun, S. B. Lee, J. A. Antonino-Daviu, J. PonsLlinares, "Reliable detection of induction motor rotor faults under the rotor axial air duct influence", , IEEE Transactions on Industry Applications, Vol. 50, No. 4, pp. 2493-2502, 2014

[23] J. A. Antonino-Daviu, V. Climente-Alarcon, J. Pons-Llinares, E. J. Wiedenbrug, "Advanced rotor assessment of motors operating under variable load conditions in mining facilities", 2014 IEEE Energy Conversion Congress and Exposition (ECCE), Pittsburgh, USA, pp. 617621, November 13, 2014

[24] M. Thomas, Fiabilite, Maintenance Predictive et Vibration des Machines, PUQ, 2012 (in French)

[25] B. Boashash, Time-Frequency Signal Analysis and Processing: A Comprehensive Reference,Academic Press, 2015

[26] C. Migeon, Emission Acoustique et Analyse Vibratoire Pour l' Etude des Defauts de Roulements pour Differents Regimes Moteurs, MSc Thesis, Universite de Reims Champagne-Ardenne, 2011 (in French) 